\title{
Poda e raleio manual de tangerineira (Citrus deliciosa Tenore) cv. Montenegrina no Sudoeste do Paraná
}

\author{
Rafael Dalla Rosa', Gilmar Antônio Nava²*, André Luiz Piva, Éder Júnior Mezzalira’, Dalva Paulus ${ }^{2}$
}

\section{RESUMO}

O bom calibre e a coloração adequada dos frutos cítricos para consumo in natura são importantes fatores de qualidade que elevam o seu consumo e melhoram os preços do produto. Este trabalho teve como objetivo avaliar o efeito de diferentes intensidades de raleio manual dos frutos e da poda sobre a produção e qualidade dos frutos da tangerina Montenegrina. O experimento foi realizado em pomar comercial no município de Dois Vizinhos, no Sudoeste do Paraná. O experimento bifatorial (raleio x poda) constituiu-se dos seguintes tratamentos. 1) sem raleio e sem poda (testemunha); 2) sem raleio, com poda; 3) 33\% de raleio, sem poda; 4) 33\% de raleio, com poda; 5) 66\% de raleio, sem poda; e 6) $66 \%$ de raleio, com poda. O delineamento experimental foi de blocos completamente casualizados, com quatro repetições, sendo cada unidade experimental constituída por uma planta. Nas condições em que o experimento foi realizado, concluiu-se que o raleio nas intensidades de 33 e $66 \%$ promove aumento da massa fresca, melhora a cor da epiderme, aumenta o diâmetro e melhora a classificação comercial dos frutos da tangerina Montenegrina. A poda leve, de abertura e levantamento da base da copa, não contribui para a melhoria da qualidade dos frutos.

Palavras-chave: citros, qualidade, classificação comercial, calibre.

\section{ABSTRACT \\ Pruning and hand thinning of 'Montenegrina' mandarin (Citrus deliciosa Tenore) in Southwest of Paraná, Brazil}

The good size and adequate color of fresh citrus are important factors of quality that increase their consumption and improve the prices received by farmers. This work aimed to study the effect of different intensities of thinning and pruning of fruit on production and fruit quality of mandarin 'Montenegrina'. The experiment was conducted in a commercial orchard in the city of Dois Vizinhos, in Southwestern Paraná, Brazil. The factorial experiment consisted of the following treatments. 1) Without thinning and without pruning (control), 2) Without thinning, with pruning; 3 ) 33 $\%$ thinning, without pruning; 4) $33 \%$ thinning, with pruning; 5) 66,\% thinning, without pruning; 6) $66 \%$ thinning, with pruning. The experimental design was completely randomized block with four replications and each experimental unit consists of one plant. Under conditions in which the experiment was conducted, it appears that the thinning intensities of $33 \%$ and $66 \%$ promote an increase in the fresh weight, improve the skin color, increase the diameter and improve the commercial classification of fruis of 'Montenegrina' mandarin. Light pruning does not contribute to improving the quality of the fruits.

Key words: citrus, quality, commercial classification, caliber.

\footnotetext{
Recebido para publicação em 25/05/2011 e aprovado em 09/02/2012

${ }^{1}$ Acadêmico do Curso Superior de Tecnologia em Horticultura. Universidade Tecnológica Federal do Paraná, Campus Dois Vizinhos, Estrada para Boa Esperança, Km 04, 85600000, CP 157, Dois Vizinhos, Paraná, Brasil. Rafaelfor1@ @otmail.com

'Engenheiro-Agrônomo, Doutor. Universidade Tecnológica Federal do Paraná, Campus Dois Vizinhos, Estrada para Boa Esperança, Km 04, 85600-000, CP 157, Dois Vizinhos, Paraná, Brasil. gilmarnava@utfpr.edu.br; dalvaufsmdeutch@yahoo.com.br*autor para correspondência.

${ }^{3}$ Tecnólogo em Horticultura. Universidade Estadual do Oeste do Paraná (Unioeste), Campus Marechal Cândido Rondon, Rua Pernambuco, 1777, Centro, 85960-000, Marechal Cândido Rondo, Paraná, Brasil. eder.mezzalira@gmail.com, andrepv8@gmail.com
} 


\section{INTRODUÇÃO}

No Sudoeste do Paraná, bem como em outras regiões do Centro-Sul do País, vem aumentando o interesse no cultivo de citros, especialmente de tangerinas. Na primeira região, esse comportamento é devido, principalmente, ao solo fértil e ao clima favorável para o cultivo de citros na região, que apresenta boa amplitude térmica diária, o que imprime boa qualidade nas tangerinas em relação à cor da epiderme e ao sabor.

$\mathrm{Na}$ produção de citros para o mercado in natura, a qualidade da fruta é requisito fundamental. O sabor, o aroma, a aparência externa, o valor nutritivo, o preço e a ausência de resíduos químicos e biológicos são os fatores que mais influenciam na decisão de compra de uma fruta pelo consumidor, determinando também o preço recebido pelo produtor (Guardiola \& Garcia-Luis, 2000).

No entanto, a tangerina Montenegrina (Citrus deliciosa Tenore) apresenta o fenômeno de alternância de produção, que é caracterizado pela produção excessiva de frutos num ano, seguido de outro ano com produção muito baixa ou nula. Nos anos de florescimento excessivo, os frutos são de baixa qualidade, pequenos, de coloração deficiente, aguados e ácidos (Koller, 1994).

$\mathrm{O}$ raleio de frutos, associado ou não à poda, normalmente torna as plantas mais bem equilibradas, capazes de produzir frutos de maior calibre e melhor coloração, além de facilitar o processo de colheita e melhorar as condições fitossanitárias do pomar, o que asseguraria melhor remuneração ao produtor de frutos cítricos de mesa (Caetano, 1991; Rabe, 1991; Coelho \& Medina, 1992; Marinho et al., 1993; Gazzola \& Souza, 1994).

A intensidade de raleio manual, em geral, depende da carga de frutos das plantas e da capacidade do cultivar copa e do porta-enxerto nutrir satisfatoriamente os frutos remanescentes após o raleio (Koller, 1994). De acordo com Rodrigues et al. (1998), o raleio manual de tangerinas Montenegrina em Eldorado do Sul, RS, na intensidade de $66,6 \%$, foi o mais eficiente na estabilização da produção de frutos comercializáveis em plantas com carga inicial mediana, e o raleio na intensidade de $83,3 \%$ proporcionou melhores resultados em plantas com carga inicial alta, ambos exigindo repetição a cada dois anos.

Quanto à época de execução do raleio manual, acredita-se que os resultados sejam tanto melhores quanto mais cedo for executado após a formação dos frutinhos. No entanto, frutos pequenos dificultam a sua localização entre a folhagem densa, dificultando o raleio. Por isso, prefere-se fazer o raleio quando os frutinhos possuem de 1,5 a 2,5 cm de diâmetro (Koller, 1994). O raleio tardio pode reduzir o tamanho final dos frutos remanescentes na colheita, uma vez que parte das reservas de carboidratos na planta já foi transportada e utilizada pelos frutos raleados (Ruiz et al., 2001).
Este trabalho teve como objetivo avaliar o efeito de diferentes intensidades de raleio manual de frutos e da poda sobre a produção e qualidade dos frutos da tangerineira Montenegrina na região Sudoeste do Paraná.

\section{MATERIAL E MÉTODOS}

O experimento foi realizado em um pomar comercial localizado a cerca de $5 \mathrm{~km}$ da Universidade Tecnológica Federal do Paraná, Campus de Dois Vizinhos, na região ecoclimática do Sudoeste do Paraná (latitude de $25^{\circ} 42^{\prime} \mathrm{S}$, longitude de $53^{\circ} 06^{\prime} \mathrm{W}$ e altitude média de $520 \mathrm{~m}$ ) (Inmet, 2009). O clima da região pertence ao subgrupo Cfa subtropical úmido com verão quente, pela classificação de Köppen. O solo do pomar é classificado como Nitossolo Vermelho-Distroférrico típico (Embrapa-CNPS, 2006).

O experimento foi constituído de um arranjo bifatorial, sendo o fator raleio manual com três níveis: 1- sem raleio; 2 - raleio de $33 \%$ dos frutos; e 3 - raleio de $66 \%$ dos frutos. O fator poda constou de dois níveis: 1- poda leve e 2- sem poda leve de abertura e levantamento da base da copa. Na poda de abertura da copa retiraram-se de três a cinco ramos com diâmetro basal de 2 a $4 \mathrm{~cm}$ para permitir maior entrada de luz e ventilação no seu interior. Na poda de levantamento da base da copa retiraram-se os ramos que estavam em contato direto e/ou entrando em contato com o solo. O delineamento experimental foi o de blocos completamente casualizados, com quatro repetições, sendo cada unidade experimental constituída por uma planta. As plantas de tangerineiras utilizadas foram do cultivar Montenegrina enxertadas sobre o porta-enxerto Poncirus trifoliata, plantas essas, não alternantes, com oito anos, em plena produção.

O experimento foi implantado com as operações de raleio e poda no dia 22 de dezembro de 2009, encerrandose com a colheita em dois repasses e avaliação de rendimento e qualidade dos frutos (nos dias 03/09 e 17/09). O raleio foi realizado quando os frutos estavam com diâmetro médio de aproximadamente $2 \mathrm{~cm}$. Para a contagem do total de frutos por planta e efetivação dos percentuais de raleio pré-estabelecidos, foram passados dois segmentos de corda sobre a copa das plantas, tendo elas sido divididas em quatro quadrantes para facilitar a contagem do número de frutos por planta. Posteriormente, calculou-se o número de frutos a serem raleados de cada planta.

Foram analisados os componentes de rendimento (frutos/planta remanescentes após o raleio, massa média de frutos e rendimento de suco), e a qualidade físico-química (cor da epiderme, SST, ATT, relação SST/ATT), bem como a classificação comercial dos frutos.

Para avaliar os componentes de rendimento, foram colhidos todos os frutos e retirada amostra com 50 frutos de cada unidade experimental, os quais foram pesados em balança semianalítica para a obtenção da massa média de 
frutos e da produção por planta $(\mathrm{kg})$, com base no número total de frutos colhidos.

A partir dessas amostras de frutos foram obtidos os teores de sólidos solúveis totais (SST), a acidez total titulável (ATT), relação SST/ATT e cor da epiderme. Os teores de SST $\left({ }^{\circ}\right.$ Brix) foram obtidos através de refratômetro digital, a partir de uma alíquota (gota) de suco extraída dos frutos por centrifugação. A ATT $(\%)$ foi determinada por meio da titulação de $10 \mathrm{~mL}$ de suco $+90 \mathrm{~mL}$ de água destilada com a solução de $\mathrm{NaOH}$ 0,1 N até pH 8,1.

A cor de fundo da epiderme foi determinada com auxílio de uma escala manual de cores variando de verde a alaranjada intensa, sendo: 1- alaranjada intensa (muita cor); 2- amarela-alaranjado (cor intermediária) e; 3- amarelaesverdeado (fruto verdoengo).

A classificação comercial dos frutos foi feita a partir de uma amostra de 50 frutos em categorias, com base no seu diâmetro transversal (CAT 1: > 67 mm; CAT 2: 57-67 mm; CAT 3: 48-56 mm; e refugo: < $48 \mathrm{~mm}$ ), conforme Schwarz et al. (1992). O diâmetro transversal de cada um dos 50 frutos de cada amostra experimental foi obtido com auxílio de paquímetro digital.

O percentual de rendimento de suco das frutas foi obtido por meio da sua extração com centrífuga do tipo 'Juicer' de todo o suco dos frutos da amostra (a partir das frutas descascadas) e de sua separação das sementes, do bagaço e da casca, em relação ao peso total dos frutos intactos da amostra.

Também foram coletados dados horários de temperatura a partir de uma estação meteorológica automatizada no Campus Dois Vizinhos da UTFPR, localizada a cerca de $5 \mathrm{~km}$ em linha reta das plantas do pomar estudado. No presente experimento utilizou-se dados de temperatura do período de 21/07/10 a 31/08/10 referentes aos últimos 40 dias que se antecederam ao período médio de colheita dos frutos.

Os dados coletados das variáveis primárias foram submetidos à análise de variância (ANOVA), e as médias de tratamentos foram comparadas pelo teste de Tukey a 5\% de probabilidade de erro, com auxílio do pacote estatístico SAS (Sas Institute, 1999).

\section{RESULTADOS E DISCUSSÃO}

De acordo com a ANOVA, não houve interações entre os fatores raleio e poda para as variáveis avaliadas. Verificou-se também que a poda isoladamente, na intensidade em que foi realizada (poda leve), não interferiu em nenhuma das variáveis avaliadas (Tabelas 1 a 4), apesar das grandes diferenças numéricas entre os dois níveis de poda para as variáveis número de frutos colhidos e produção por planta, que foram de 193 frutos $(P R>F=0,067)$ e de $18,67 \mathrm{~kg}(\mathrm{PR}>\mathrm{F}=0,083)$, respectivamente, evidenciarem o efeito da poda na redução da produção de frutos das plantas (Tabela 1). Sartori et al. (2007) observaram que a poda anual de frutificação em plantas excessivamente carregadas, suprimindo galhos para promover a entrada de luz e retirando de 30 a $40 \%$ dos ramos produtivos terminais nos galhos remanescentes, apesar de diminuir a produção por planta, melhorou a qualidade dos frutos. Esse efeito menos evidente que o da poda de ramos produtivos terminais sobre as variáveis avaliadas pode ser

Tabela 1. Número de frutos colhidos e da produção por planta de tangerineira Montenegrina em resposta à poda e ao raleio de frutos. Dois Vizinhos, Paraná, 2011

\begin{tabular}{|c|c|c|c|}
\hline \multirow{3}{*}{ Intensidade de raleio } & \multicolumn{3}{|c|}{ Número de frutos colhidos por planta } \\
\hline & \multicolumn{2}{|c|}{ Poda } & \multirow{2}{*}{ Média } \\
\hline & Com & Sem & \\
\hline Sem & 906 & 1.094 & $1.000 \mathrm{a}$ \\
\hline $33 \%$ & 826 & 1.140 & $983 \mathrm{ab}$ \\
\hline $66 \%$ & 646 & 720 & $683 \mathrm{~b}$ \\
\hline Média & $792 \mathrm{~A}$ & $985 \mathrm{~A}(\mathrm{PR}>\mathrm{F}=0,067)$ & 889 \\
\hline \multirow[t]{2}{*}{$\mathrm{CV}(\%)$} & \multicolumn{3}{|c|}{26,82} \\
\hline & & Produção (kg.planta-1) & \\
\hline \multirow[t]{2}{*}{ Intensidade de raleio } & \multicolumn{2}{|c|}{ Poda } & \multirow{2}{*}{ Média } \\
\hline & Com & Sem & \\
\hline Sem & 91,27 & 100,10 & $95,68 \mathrm{ab}$ \\
\hline $33 \%$ & 91,37 & 129,59 & 110,48 a \\
\hline $66 \%$ & 69,82 & 78,77 & $74,29 \mathrm{~b}$ \\
\hline Média & $84,15 \mathrm{~A}$ & $102,82 \mathrm{~A}(\mathrm{PR}>\mathrm{F}=0,083)$ & 93,48 \\
\hline$\overline{\mathrm{CV}(\%)}$ & & 26,32 & \\
\hline
\end{tabular}

* Médias seguidas da mesma letra maiúscula na linha e de minúscula na coluna não diferem estatisticamente pelo teste de Tukey a $5 \%$ de probabilidade de erro.

Rev. Ceres, Viçosa, v. 59, n.2, p. 254-261, mar/abr, 2012 
atribuído à poda mais branda (sem a realização da poda de ramos produtivos depois da supressão dos galhos maiores), bem como pela baixa carga relativa de frutos observada nas plantas do presente estudo.

Para o número de frutos colhidos por planta, somente se verificou diferenças significativas entre o tratamento testemunha e com $66 \%$ de raleio. As plantas submetidas ao raleio na intensidade de $33 \%$ apresentaram número de frutos intermediário aos dos tratamentos anteriores. A ausência de diferenças estatísticas entre os tratamentos testemunha versus $33 \%$ de raleio e entre os tratamentos com $33 \%$ versus $66 \%$ de raleio pode ter sido devida ao maior número de frutos nas plantas testemunhas e, ou, à baixa eficiência do raleio nas plantas com $33 \%$ de raleio pré-estabelecido (Tabela 1). Nesse sentido, o raleio manual está sujeito a erros, devido à dificuldade de encontrar os frutos camuflados entre a vasta folhagem das plantas de Montenegrina, mesmo tendo sido efetuado o raleio quando os frutos apresentavam cerca de $20 \mathrm{~mm}$ de diâmetro. Esse fator faz com que permaneça na planta, geralmente, maior número de frutos em relação ao desejado, principalmente quando elas estão muito carregadas de frutos e quando se deseja ralear maior quantidade deles.

Para a massa fresca média de frutos, pode-se observar que o raleio manual nas intensidades de $33 \%$ e $66 \%$ apresentou as maiores médias, de 111,49g e 109,18 g, respecti-

Tabela 2. Massa fresca média, diâmetro transversal, índice de cor e rendimento de suco de tangerina Montenegrina em resposta à poda e ao raleio de frutos. Dois Vizinhos, Paraná, 2011

\begin{tabular}{|c|c|c|c|}
\hline \multirow{3}{*}{ Intensidade de raleio } & \multicolumn{3}{|c|}{ Massa fresca dos frutos (g) } \\
\hline & \multicolumn{2}{|c|}{ Poda } & \multirow{2}{*}{ Média } \\
\hline & Com & Sem & \\
\hline Sem & 100,45 & 91,80 & $96,13 \mathrm{~b}$ \\
\hline $33 \%$ & 108,58 & 114,40 & $111,49 \mathrm{a}$ \\
\hline $66 \%$ & 109,50 & 108,85 & $109,18 \mathrm{a}$ \\
\hline Média & $106,18 \mathrm{~A}$ & $105,01 \mathrm{~A}$ & 105,60 \\
\hline \multirow[t]{2}{*}{$\mathrm{CV}(\%)$} & \multicolumn{3}{|c|}{9,27} \\
\hline & \multicolumn{3}{|c|}{ Diâmetro transversal (mm) } \\
\hline \multirow[t]{2}{*}{ Intensidade de raleio } & \multicolumn{2}{|c|}{ Poda } & \multirow{2}{*}{ Média } \\
\hline & Com & Sem & \\
\hline Sem & 59,58 & 56,03 & $57,81 \mathrm{~b}$ \\
\hline $33 \%$ & 62,32 & 61,75 & $62,04 \mathrm{a}$ \\
\hline $66 \%$ & 62,47 & 61,93 & $62,20 \mathrm{a}$ \\
\hline Média & $61,45 \mathrm{~A}$ & $59,90 \mathrm{~A}$ & 60,68 \\
\hline \multirow[t]{2}{*}{$\mathrm{CV}(\%)$} & \multicolumn{3}{|c|}{2,98} \\
\hline & & dice de co & \\
\hline \multirow[t]{2}{*}{ Intensidade de raleio } & \multicolumn{2}{|c|}{ Poda } & \multirow{2}{*}{ Média } \\
\hline & Com & Sem & \\
\hline Sem & 2,45 & 2,61 & $2,53 \mathrm{a}$ \\
\hline $33 \%$ & 2,07 & 2,28 & $2,17 \mathrm{~b}$ \\
\hline $66 \%$ & 1,69 & 1,67 & $1,68 \mathrm{c}$ \\
\hline Média & $2,07 \mathrm{~A}$ & $2,19 \mathrm{~A}$ & 2,13 \\
\hline \multirow[t]{2}{*}{$\mathrm{CV}(\%)$} & \multicolumn{3}{|c|}{11,84} \\
\hline & & ento de st & \\
\hline \multirow[t]{2}{*}{ Intensidade de raleio } & \multicolumn{2}{|c|}{ Poda } & \multirow{2}{*}{ Média } \\
\hline & Com & Sem & \\
\hline Sem & 63,6 & 64,7 & $64,2 \mathrm{a}$ \\
\hline $33 \%$ & 63,0 & 64,2 & $63,6 \mathrm{a}$ \\
\hline $66 \%$ & 61,0 & 65,9 & $63,3 \mathrm{a}$ \\
\hline Média & $62,59 \mathrm{~A}$ & $65,00 \mathrm{~A}$ & 63,80 \\
\hline $\mathrm{CV}(\%)$ & & 5,52 & \\
\hline
\end{tabular}

* Medias seguidas da mesma letra maiúscula na linha e de minúscula na coluna não diferem estatisticamente pelo teste de Tukey a 5\% de probabilidade de erro. ** Índices de cor da epiderme dos frutos: 1- alaranjado intenso; 2- amarelo-alaranjado; e 3- amarelo-esverdeado. 
vamente, sem diferença significativa entre si; entretanto diferindo estatisticamente da testemunha (sem raleio) em que os frutos apresentaram massa fresca média de 96,13 g (Tabela 2).

Para o diâmetro transversal de frutos, as duas intensidades de raleio avaliadas foram efetivas em aumentar o calibre dos frutos, pois o diâmetro foi de $62,20 \mathrm{~mm}$ e 62,04 $\mathrm{mm}$ para as intensidades de raleio de $66 \%$ e $33 \%$, respectivamente, contra $57,81 \mathrm{~mm}$ no tratamento testemunha, tendo sido aquelas diferentes estatisticamente da testemunha (Tabela 2). Como explicação para os dados obtidos, acredita-se que o fator raleio gerou menor competição nutricional entre os frutos, permitindo o seu maior crescimento. Esse fator influenciou positivamente sobre a classificação comercial dos frutos.

Segundo Rufini \& Ramos (2002), o raleio manual nas intensidades entre 50 e $80 \%$ também promoveu incremento no tamanho e na massa fresca de frutos, tendo a produção (kg/planta) sido diminuída à medida que aumentou a intensidade de raleio. Schwarz et al. (1992) e Sartori et al. (2007) também verificaram que o raleio manual de 66\% aumentou o calibre e a massa fresca dos frutos de tange- rina Montenegrina. De acordo com Rodrigues et al. (1998), para plantas com carga inicial mediana (como as observadas neste experimento), o raleio manual de $66,6 \%$ dos frutos foi eficiente na estabilização da produção de frutos comercializáveis, devendo ser repetido, no mínimo, a cada dois anos. Já para plantas muito carregadas, são necessárias intensidades maiores de raleio para a obtenção de resultados satisfatórios de calibre de frutos e de estabilidade produtiva das plantas ao longo dos anos.

Para o índice de cor dos frutos, verificou-se que o raleio manual na intensidade de $66 \%$ promoveu o melhor índice $(1,68)$, seguido dos tratamentos com $33 \%$ de raleio (2,17 - intermediário) e do tratamento testemunha, que apresentou o pior resultado $(2,53)$ (Tabela 2). Nesse sentido, a melhor distribuição dos frutos na planta permitiu menor competição entre eles, gerando maior saldo energético líquido para a biossíntese de pigmentos carotenoides, além da maior interceptação direta de luz pelos frutos.

Quanto ao rendimento de suco, a exemplo do que ocorreu com a poda, não se observou efeito significativo dos níveis de raleio (Tabela 2). No entanto, pôde-se verificar

Tabela 3. Teores de sólidos solúveis totais (SST), acidez total titulável (ATT) e relação SST/ATT em resposta à poda e ao raleio de frutos. Dois Vizinhos, Paraná, 2011

\begin{tabular}{|c|c|c|c|}
\hline \multirow{3}{*}{ Intensidade de raleio } & \multicolumn{3}{|c|}{ SST $\left({ }^{\circ}\right.$ Brix $)$} \\
\hline & \multicolumn{2}{|c|}{ Poda } & \multirow[b]{2}{*}{ Média } \\
\hline & Com & Sem & \\
\hline$\overline{\text { Sem }}$ & 11,32 & 11,06 & $11,20 \mathrm{a}$ \\
\hline $33 \%$ & 11,17 & 11,07 & $11,13 \mathrm{a}$ \\
\hline $66 \%$ & 11,47 & 11,50 & $11,49 \mathrm{a}$ \\
\hline Média & $11,32 \mathrm{~A}$ & $11,21 \mathrm{~A}$ & 11,25 \\
\hline \multirow[t]{2}{*}{$\mathrm{CV}(\%)$} & \multicolumn{3}{|c|}{3,59} \\
\hline & & $\operatorname{ATT}(\%$ & \\
\hline \multirow[t]{2}{*}{ Intensidade de raleio } & \multicolumn{2}{|c|}{ Poda } & \multirow{2}{*}{ Média } \\
\hline & Com & Sem & \\
\hline Sem & 1,39 & 1,40 & $1,40 \mathrm{a}$ \\
\hline $33 \%$ & 1,38 & 1,44 & $1,42 \mathrm{a}$ \\
\hline $66 \%$ & 1,51 & 1,46 & $1,49 \mathrm{a}$ \\
\hline Média & $1,43 \mathrm{~A}$ & $1,43 \mathrm{~A}$ & 1,43 \\
\hline \multirow[t]{2}{*}{$\mathrm{CV}(\%)$} & \multicolumn{3}{|c|}{8,25} \\
\hline & & ST/AT & \\
\hline \multirow[t]{2}{*}{ Intensidade de raleio } & \multicolumn{2}{|c|}{ Poda } & \multirow{2}{*}{ Média } \\
\hline & Com & Sem & \\
\hline Sem & 8,13 & 7,98 & $8,06 \mathrm{a}$ \\
\hline $33 \%$ & 8,12 & 7,68 & $7,90 \mathrm{a}$ \\
\hline $66 \%$ & 7,60 & 7,85 & $7,73 \mathrm{a}$ \\
\hline Média & $7,95 \mathrm{~A}$ & $7,84 \mathrm{~A}$ & 7,90 \\
\hline $\mathrm{CV}(\%)$ & & 7,74 & \\
\hline
\end{tabular}

*Medias seguidas da mesma letra maiúscula na linha e de minúscula na coluna não diferem estatisticamente pelo teste de Tukey a 5\% de probabilidade de erro.

Rev. Ceres, Viçosa, v. 59, n.2, p. 254-261, mar/abr, 2012 
que o percentual médio de rendimento de suco obtido dos frutos de Montenegrina no experimento $(63,8 \%)$ foi muito superior ao observado por Sartori et al. (2007) para o mesmo cultivar, que foi de 47,07\%. Segundo Magalhães et al. (2005), o teor mínimo de suco para a definição do ponto de colheita de laranjas e tangerinas é de 35-45\%. Assim, pode-se inferir que a qualidade da tangerina Montenegrina produzida no Sudoeste do Paraná, com base nessa variável, é muito boa.

$\mathrm{Na}$ Tabela 3, os dados mostram que o raleio manual não afetou o teor de sólidos solúveis totais (SST). Sartori et al. (1998) obteve teor médio de SST de 11,6 ${ }^{\circ}$ Brix na tangerina Montenegrina na Depressão Central do RS, ten- do esse nível sido levemente superior ao obtido no presente experimento, que foi de 11,25 ${ }^{\circ}$ Brix. Para Magalhães et al. (2005), o teor mínimo de açúcares para a definição do ponto de colheita de laranjas e tangerinas é de 9-10 ${ }^{\circ}$ Brix, tendo as frutas colhidas em todos os tratamentos do experimento apresentado os padrões mínimos exigidos pelo mercado consumidor para frutas de mesa.

Dados semelhantes foram obtidos para a ATT e para a relação SST/ATT, em que não se observou efeito do raleio de frutos para essas variáveis (Tabela 3). Para Sartori et al. (1998), o teor médio de ATT de tangerinas Montenegrina na Depressão Central do RS foi de 1,23\%, índice esse pouco abaixo do obtido no presente experi-

Tabela 4. Classificação comercial de frutos de tangerina Montenegrina em resposta à poda e ao raleio de frutos. Dois Vizinhos, Paraná, 2011

\begin{tabular}{|c|c|c|c|}
\hline \multirow{3}{*}{ Intensidade de raleio } & \multicolumn{3}{|c|}{ CAT $1(\%)$} \\
\hline & \multicolumn{2}{|c|}{ Poda } & \multirow{2}{*}{ Média } \\
\hline & Com & Sem & \\
\hline Sem & 2,00 & 0,66 & $1,33 \mathrm{~b}$ \\
\hline $33 \%$ & 14,5 & 23,00 & $18,75 \mathrm{a}$ \\
\hline $66 \%$ & 11,50 & 8,50 & $10,00 \mathrm{ab}$ \\
\hline Média & $9,33 \mathrm{~A}$ & $10,72 \mathrm{~A}$ & 10,03 \\
\hline \multirow[t]{2}{*}{$\mathrm{CV}(\%)$} & \multicolumn{3}{|c|}{115,52} \\
\hline & & CAT $2(\%$ & \\
\hline \multirow[t]{2}{*}{ Intensidade de raleio } & \multicolumn{2}{|c|}{ Poda } & \multirow{2}{*}{ Média } \\
\hline & Com & Sem & \\
\hline Sem & 70,50 & 51,33 & $60,92 \mathrm{a}$ \\
\hline $33 \%$ & 68,50 & 70,50 & $69,50 \mathrm{a}$ \\
\hline $66 \%$ & 77,50 & 78,00 & $77,75 \mathrm{a}$ \\
\hline Média & $72,16 \mathrm{~A}$ & $66,61 \mathrm{~A}$ & 69,39 \\
\hline \multirow[t]{2}{*}{$\mathrm{CV}(\%)$} & \multicolumn{3}{|c|}{19,69} \\
\hline & & CAT $3(\%$ & \\
\hline \multirow[t]{2}{*}{ Intensidade de raleio } & \multicolumn{2}{|c|}{ Poda } & \multirow{2}{*}{ Média } \\
\hline & Com & Sem & \\
\hline Sem & 27,00 & 46,66 & $31,83 \mathrm{a}$ \\
\hline $33 \%$ & 17,00 & 6,50 & $11,75 \mathrm{~b}$ \\
\hline $66 \%$ & 11,00 & 13,50 & $12,25 \mathrm{~b}$ \\
\hline Média & $18,33 \mathrm{~A}$ & $22,22 \mathrm{~A}$ & 20,28 \\
\hline \multirow[t]{2}{*}{$\mathrm{CV}(\%)$} & \multicolumn{3}{|c|}{66,69} \\
\hline & & efugo $(\%$ & \\
\hline \multirow[t]{2}{*}{ Intensidade de raleio } & Poda & Média & \multirow{2}{*}{ Média } \\
\hline & Com & Sem & \\
\hline Sem & 0,50 & 1,33 & $0,92 \mathrm{a}$ \\
\hline $33 \%$ & 0,00 & 0,00 & $0,00 \mathrm{a}$ \\
\hline $66 \%$ & 0,00 & 0,00 & $0,00 \mathrm{a}$ \\
\hline Média & $0,17 \mathrm{~A}$ & $0,44 \mathrm{~A}$ & 0,31 \\
\hline$\overline{\mathrm{CV}(\%)}$ & & 296,09 & \\
\hline
\end{tabular}

*Médias seguidas da mesma letra maiúscula na linha e de minúscula na coluna não diferem estatisticamente pelo teste de Tukey a 5\% de probabilidade de erro. 
mento, que foi de $1,44 \%$. Nas condições de clima de Dois Vizinhos, o alto índice relativo de acidez no suco dos frutos deve estar associado à grande amplitude térmica diária registrada durante o amadurecimento dos frutos (temperatura média diurna de $19,65^{\circ} \mathrm{C}$ e temperatura média noturna de $15,26^{\circ} \mathrm{C}$ ), fator que reduz a utilização dos ácidos orgânicos no processo respiratório. Segundo Magalhães et al. (2005), a relação SST/ATT mínima para a definição do ponto de colheita de laranjas e tangerinas é de 8,5-10. Nos frutos deste experimento, a relação foi um pouco abaixo $(7,9)$ desse referencial para todas as intensidades de raleio, consequência dos índices mais elevados de acidez observados nos frutos, uma vez que os teores de SST foram adequados para o enquadramento nesse padrão mínimo.

Esse fator indica a necessidade de realização da colheita duas a três semanas mais tarde, já que na região, como anteriormente dito, a amplitude térmica existente, característica da região, atrasa a maturação e favorece a acumulação de ácidos em relação a outras regiões produtoras da fruta que apresentam noites mais quentes e menor amplitude térmica diária.

Estudando a tangerina Ponkan, Rufini \& Ramos (2002) verificaram que os teores de sólidos solúveis totais, acidez titulável, relação sólidos solúveis/acidez, vitamina C, açúcares totais, $\mathrm{pH}$ e rendimento em suco também não foram alterados com a prática do raleio manual dos frutos nas intensidades entre 50 e $80 \%$.

Em consequência do efeito do raleio manual sobre o calibre dos frutos, observou-se que o raleio manual nas duas intensidades promoveu maior percentagem de frutos classificados na Categoria 1 (CAT 1), que abrange os frutos de qualidade superior de mercado; sem, no entanto, diferirem estatisticamente entre si, mas tendo o tratamento com $33 \%$ de raleio apresentado diferença estatística do tratamento testemunha, que praticamente não apresentou frutos nessa categoria (Tabela 4).

Apesar da tendência de maiores percentuais de frutos classificados na Categoria 2 (CAT 2), principalmente na intensidade de raleio de $66 \%$, em relação ao tratamento testemunha, não se verificaram diferenças estatísticas entre os tratamentos. Essa categoria foi a que apresentou o maior percentual de frutos (Tabela 4).

Um fator positivo é que o raleio manual de frutos de $33 \%$ e $66 \%$ gerou menor quantidade de frutos pertencentes à Categoria 3 (CAT 3), em comparação com o tratamento testemunha (Tabela 4). Essa categoria, depois da categoria Refugo, representa frutos de pior qualidade comercial. Poucos foram os frutos enquadrados na categoria Refugo, não havendo diferenças significativas entre as intensidades de raleio. Cabe ressaltar, em razão do grande volume de chuvas ocorridas no pomar, que a taxa de vingamento de frutos não foi muito elevada na safra
2009/2010, gerando plantas com carga média de 1.367 frutos (dados não mostrados), bem abaixo do esperado na maioria dos anos em plantas adultas bastante carregadas e não raleadas, que podem chegar a produzir próximo a 3.000 frutos. Esse fator pode ter sido responsável pelas pequenas diferenças percentuais de frutos nas mais diversas classificações comerciais.

\section{CONCLUSÕES}

O raleio manual nas intensidades de $33 \%$ e $66 \%$ incrementa o tamanho e a coloração, sem alterar as características do suco dos frutos de tangerina cv. Montenegrina.

A poda leve, de abertura e levantamento da base da copa, não contribui para a melhoria da qualidade dos frutos da tangerina Montenegrina.

Os frutos de tangerina Montenegrina produzidos no Sudoeste do Paraná apresentam os padrões mínimos de qualidade exigidos pelo mercado Brasileiro.

\section{REFERÊNCIAS}

Caetano AA (1991) Tratos culturais. In: Rodriguez O, Viegas FCP, Pompeu Júnior J \& Amaro A.A (Eds.) Citricultura Brasileira. 2a ed. Campinas, Fundação Cargill. p.429-466.

Coelho YS \& Medina VM (1992) Desbaste de Frutos. In: $2^{\circ}$ Seminário Internacional de Citros - Fisiologia, Campinas. Anais, Fundação Cargill. p.187-194.

Embrapa - Centro Nacional de Pesquisa de Solos (CNPS) (2006) Sistema Brasileiro de Classificação de Solos. $2^{\text {a }}$ ed. Rio de Janeiro, Embrapa Solos. 412p.

Gazzola R \& Souza M de (1994) Adubação foliar e desbaste em Tangerineira (Citrus reticulata Blanco, cv. Ponkan). Pesquisa Agropecuária Brasileira, 29:785-890.

Guardiola JL \& García-Luis A (2000) Increasing fruit size in Citrus: thinning and stimulation of fruit growth. Plant Growth Regulation, 31:121-132.

Inmet (2009) Estação meteorológica A843 de Dois Vizinhos, PR. Disponível em: <http://www.inmet.gov.br/sonabra/sonabra.html>. Acessado em: 20 de outubro de 2009.

Koller OC (1994) Citricultura: Laranja, limão e tangerina. Porto Alegre, Rigel. 446p

Magalhães AFJ, Nascimento, AS, Ritzinger, CHSP et al. (2005) Sistema de produção para pequenos produtores de citros do Nordeste. Disponível em <http://sistemasdeproducao.cnptia.embrapa.br/ FontesHTML/Citros/CitrosNEPequenosProdutores/colheita.htm>. Acessado em: 01 de dezembro de 2010.

Marinho CS, Souto RF \& Souza Sobrinho F (1993) Influência da adubação foliar e desbaste manual na qualidade dos frutos da Tangerineira (Citrus reticulata Blanco, cv. Poncã). Pesquisa Agropecuária Brasileira, 28:1019-1023.

Rabe E (1991) Fruit size improvement in 'Valencia' and 'Tomango' orange cultivars [Citrus sinensis (L.) Osbeck] through handthinning of fruitlets in November-December. Journal of the Southern African Society for Horticultural Sciences, 1:59-63.

Rodrigues L, Schwarz SF, Reckziegel VP \& Koller OC (1998) Raleio manual de frutos de tangerinas 'Montenegrina'. Pesquisa Agropecuária Brasileira, 33:1315-1320. 
Rufini JCM \& Ramos JD (2002) Influência do raleio manual sobre a qualidade dos frutos da tangerineira 'Ponkan' (Citrus reticulata blanco). Ciência e Agrotecnologia, 26:516-522.

Ruiz R, García-Luis A, Monerri C \& Guardiola JL (2001) Carbohydrate availability in relation to fruitlet abscission in Citrus. Annals of Botany, 87:805-812.

Sartori IA, Koller OC, Theisen S, Souza PVD, Bender RJ \& Marodin GAB (2007) Efeito da poda, raleio de frutos e uso de fitorreguladores na produção de tangerineiras (Citrus deliciosa Tenore) cv. Montenegrina. Revista Brasileira de Fruticultura, 29:5-10.
Sartori IA, Shäfer Gilmar, Schwarz SF \& Koller OC (1998) Épocas de maturação de tangerinas na Depressão Central do Rio Grande do Sul. Revista Brasileira de Fruticultura, 20:313-322.

Sas Institute (1999) SAS user's guide statistics: versão 8.0 edition. Cary. $956 \mathrm{p}$.

Schwarz SF, Koller OC \& Nienow AA (1992) Intensidades e épocas de raleio manual em tangerineira 'Montenegrina'. Pesquisa Agropecuária Brasileira, 27:1161-1165. 